\title{
HISTORIOGRAFIAS URBANAS CONTRA HEGEMÔNICAS Raça e Colonialidade nos processos históricos urbanos na América \\ Latina
}

\author{
COUNTER HEGEMONIC URBAN HISTORIOGRAPHIES \\ Race and Coloniality in historical urban processes in Latin \\ America
}

\author{
A. Juliana Marques \\ Universidade Federal de Minas Gerais, Brasil \\ julianamarques@gmail.com
}

\section{RESUMO}

Esse artigo propõe-se a analisar como poder-se-ia, partir de uma perspectiva da história urbana e da teoria urbana, analisar a manutenção de estruturas coloniais, ou as colonialidades, no planejamento urbano latinoamericano, especialmente em termos de raça e classe. Estruturas coloniais são marcadoras de uma posição subalterna da América Latina, mas também fundamentais para a preservação do status quo das elites dos países latino-americanos. As contradições desse sistema marcam a produção do espaço, portanto uma dialética espacial que também fizesse a intersecção com os estudos pós-coloniais surge aqui como uma forma possível de se debruçar sobre o problema.

Palavras-chave: história urbana, colonialidade, raça, América Latina.

Linha de Investigação: 1: Cidade e projeto

Tópico: História Urbana e História do Urbanismo

\section{ABSTRACT}

This article aims to analyze how one could, from a perspective of urban history and urban theory, analyze the maintenance of colonial structures, or colonialities, in Latin American urban planning, especially in terms of race and class. Colonial structures are markers of a subordinate position in Latin America, but also fundamental for the preservation of the status quo of the elites of Latin American countries. The contradictions of this system mark the production of space, so a spatial dialectic that would also intersect with post-colonial studies appears here as a possible way of addressing the problem.

Keywords: urban history, coloniality, race, Latin America.

Thematic clusters: 1 : City and Project

Topic: Urban History and History of Urbanism 


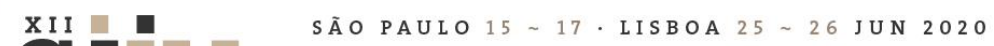

\section{Introdução}

Para partir rumo à proposição sobre o problema de uma historiografia urbana contra-hegemônica, tomemos duas imagens: a primeira é uma descrição textual, feita pelo psicanalista martinicano Frantz Fanon, na obra "Os condenados da terra", da cidade produzida pela colonização de povoamento do Império Francês no Magreb Argelino:

A cidade do colono é uma cidade sólida, tôda de pedra e ferro. É uma cidade iluminada, asfaltada, onde caixotes do lixo regurgitam de sobras desconhecidas, jamais vistas, nem mesmo sondadas. Os pés do colono nunca estão à mostra, salvo talvez no mar, mas nunca ninguém e: está bastante próximo dêles. Pés protegidos por calçados fortes, enquanto que as ruas de sua cidade são limpas, lisas, sem buracos, sem seixos. A zona habitada pelos colonizados não é complementar da zona habitada pelos colonos. Estas duas zonas se opõem, mas não em função de uma unidade superior. Regidas por uma lógica puramente aristotélica, obedecem ao princípio da exclusão recíproca: não há conciliação possível, um dos termos é demais. (Fanon, 1979, p. 28)

A cidade do colonizado, ou pelo menos a cidade indígena, a cidade negra, a médina, a reserva, é um lugar mal afamado, povoado de homens mal afamados. Aí se nasce não importa onde, não importa como. Morre-se não importa onde, não importa de quê. É um mundo sem intervalos, onde os homens estão uns sôbre os outros, as casas umas sobre as outras. A cidade do colonizado é uma cidade faminta, faminta de pão, de carne, de sapatos, de carvão, de luz. (Fanon, 1979, p. 29)

A segunda é uma fotografia relativamente recente, do fotógrafo brasileiro Tuca Vieira. Em 2004, aquele fotógrafo publicou uma foto que se tornaria clássica por ilustrar a segregação urbana brasileira: um condomínio de luxo no bairro Morumbi, em São Paulo, com uma piscina em cada varanda dos apartamentos, bem ao lado da favela de Paraisópolis. Espaços vizinhos, porém, profundamente apartados: de um lado, grandes áreas de lazer privativas; de outro, altíssima densidade populacional e carência de infraestrutura urbana. 


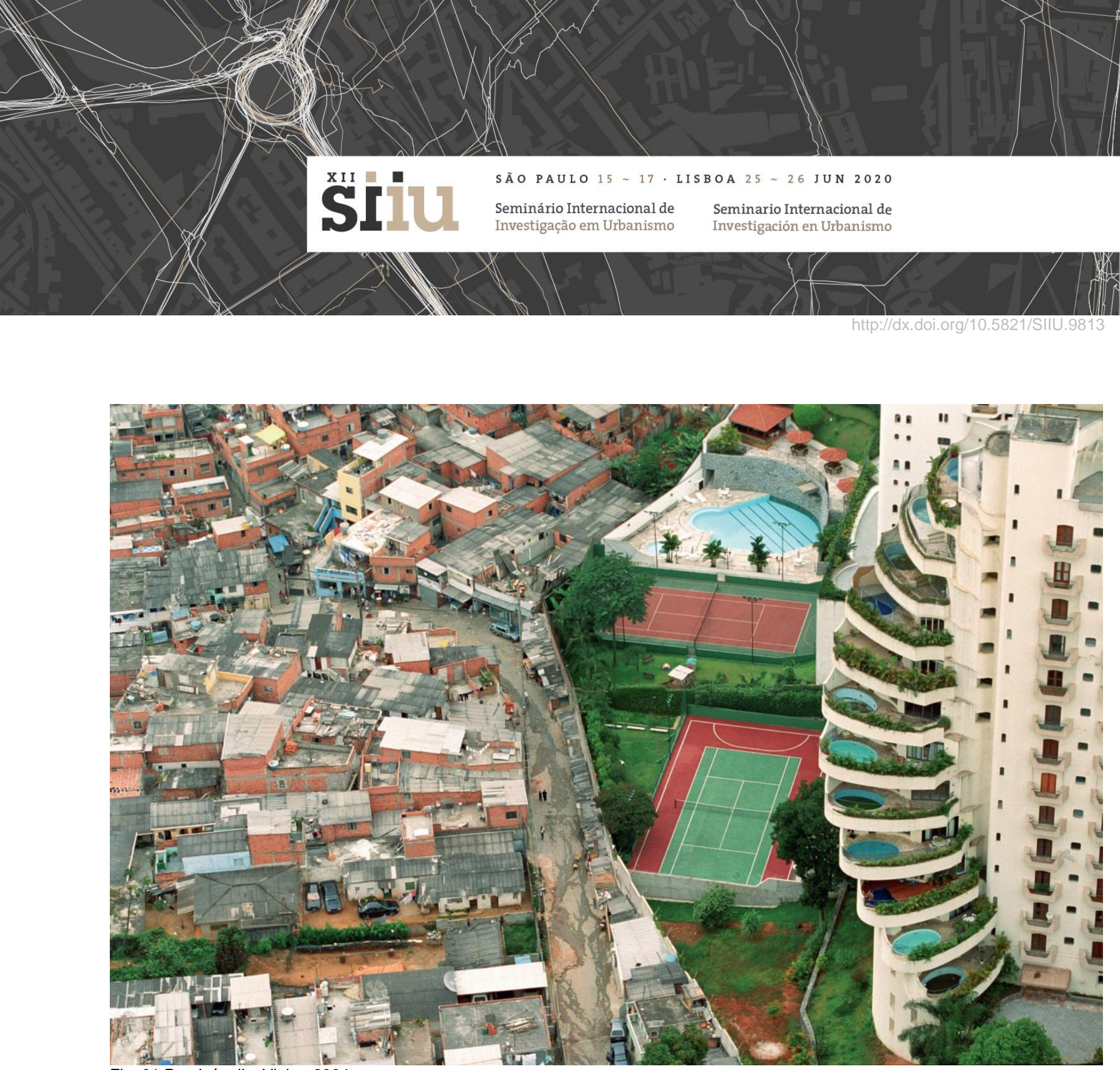

Fig. 01 Paraisópolis: Vieira, 2004

Lembremos aqui de Walter Benjamin: "O passado só se deixa fixar, como imagem que relampeja irreversivelmente, no momento em que é reconhecido" (1987, tese 5). Nas Teses Sobre o Conceito de História, Benjamin defende que uma compreensão dialética da história, contrariamente a uma compreensão historicista, passa necessariamente por compreender onde o passado irrompe no presente, identificando essas irrupções para podermos chegar ao que seria o contrapelo da narrativa histórica. Pois bem, se podemos perceber na fotografia de Vieira a irrupção da descrição de uma cidade colonial, como seria possível essa articulação entre ambas temporalidades?

\section{Que significa a permanência das estruturas coloniais nas cidades de países que passaram por processos de colonização?}

Como historiadores da cidade, e também como urbanistas, devemos considerar as particularidades da situação espacial e temporal das imagens (a fotografia e o texto) que acabamos de ver: Fanon fala de uma cidade pertencente ao contexto da colonização do império francês na África, especificamente das colônias de povoamento no Magreb argelino, na década de 1950 do século XX. A conhecida fotografia de Tuca Vieira ilustra São Paulo, a maior metrópole brasileira, e uma das maiores cidades do mundo, numa república democrática na América do Sul, no início do século XXI. Fanon fala de uma cidade com legislações específicas para a segregação entre o colonizador francês e o nativo argelino; Tuca Vieira, no caso brasileiro, 


\section{SÃO PAULO15 17 LISBOA $25 \sim 26$ JUN 2020}

capta uma cidade que, apesar da fundação no período colonial, torna-se metrópole e adquire sua conformação contemporânea já no início do século $X X$ e existe dentro de um Estado que, segundo sua constituição, considera todos igualmente cidadãos.

As duas imagens, tanto a textual como a fotográfica, descrevem uma cidade dividida: no entanto, como a estrutura territorial segregatícia, em contextos aparentemente tão distintos, pode ser tão coincidente? Como a descrição de uma cidade em meio ao jugo colonial pode servir para retratar uma metrópole, em uma República soberana e independente, meio século depois? Para responder essa questão o conceito de colonialidade, proposto pelo sociólogo peruano Aníbal Quijano (2000), torna-se crucial: colonialidades dizem respeito, pois, às estruturas de poder construídas para possibilitar o processo de colonização que permanecem no decorrer do tempo, mesmo após a independência política das metrópoles. Essas estruturas são intrínsecas ao sistema da modernidade e são elas próprias que compões a geopolítica mundial contemporânea. $O$ processo de colonização cria um padrão de dominação com o qual não conseguimos romper até os dias atuais. A partir de Luciana Ballestrin, ilustra-se abaixo como funciona o padrão de dominação denominado por Quijano de Colonialidade do Poder:

\section{$\rightarrow$ Controle da economia \\ $\rightarrow$ Controle da autoridade \\ Colonialidade do Poder $\rightarrow$ Controle da natureza e dos recursos naturais \\ $\rightarrow$ Controle do gênero e da sexualidade \\ $\rightarrow$ Controle da subjetividade e do conhecimento}

Fig. 02 Padrão de dominação: Criado com base nas informações de Ballestrin (2013, p. 100).

Conceitualmente, colonialidade abarca as estruturas criadas para a instauração do sistema colonial, como representado no diagrama acima. Esse controle externo dos recursos financeiros e naturais, da soberania de um povo, seus corpos e sua própria subjetividade, subalterniza esse grupo com o objetivo de explorar seus recursos. Tal dominação passa pelos processos tradicionais de violencia - poder militar, força física, dominação política - mas sofistica-se e conforma novas formas de violência, como o apagamento das práticas de vida coletiva daquele grupo, o silenciamento de seus saberes, a perseguição às suas crenças religiosas, a condenação de suas relações afetivas. Para marcar o grupo subalterno é necessária a criação de uma Entidade Outro distinguível e, então, sua posterior subalternização como conjunto. Dessa forma a América Latina foi laboratório e incubadora das práticas de colonização das diversas instâncias do ser que marcam a Modernidade. Nas palavras de Aníbal Quijano: "América se constituyó como el primer espacio/tiempo de un nuevo patrón de poder de vocación mundial y, de ese modo y por eso, como la primera identidad de la modernidad" (2000, p. 202).

Ao consideramos, portanto, as colonialidades, o território latino-americano pode nos contar uma história de manutenção e frutificação dessas estruturas coloniais. O espaço urbano latino-americano apresenta em comum marcas de uma profunda separação, em toda sua diversidade estilística, temporal, topográfica e cultural; separação essa facilmente identificável na epiderme e nas feições de suas populações. Sejam indígenas ou negros, os povos marcados pelo jugo colonial permanecem apartados, espacialmente, nos bairros e distritos de nossa complexa rede urbana. Nesse sentido, a cidade latino-americana se apresenta, em seu desenvolvimento histórico e em sua conformação, não somente como reflexo da segregação social produzida pelo capitalismo periférico, mas como objeto que, dialeticamente, é produzido e produz uma conformação de sociedade pós-colonial. 


\section{SÃO PAULO15 17 LISBOA 25 26 JUN 2020}

\section{Por que a "decolonização da história" se apresenta como chave historiográfica e o que significa "decolonizar a história urbana"}

Mignolo caracteriza o decolonial como "pensar a partir da exterioridade e em uma posição epistêmica subalterna vis-à-vis à hegemonia epistêmica que cria, constrói, erige um exterior a fim de assegurar sua interioridade" (2008, p. 304). Está bem estabelecido no pensamento decolonial latino-americano o pressuposto de adotar uma atitude decolonial, para além de uma metodologia, como forma de posicionamento frente aos saberes locais: sair do padrão centro-periferia que só valida os conhecimentos produzidos pelo centro (europeu e branco) e ignora aqueles produzidos fora do padrão de poder epistemológico. Porém, para além da produção teórica dos estudiosos latinos temos, ao tratar a urbe como objeto, a cidade apresenta-se não só como documento histórico, mas como ela própria, uma episteme, ou seja, uma forma de saber que condiciona vivências.

Aqui nos deparamos, simultaneamente, com um problema histórico e da teoria urbanista: como descrever, tanto na narrativa histórica, quanto na própria produção dessa narrativa, a construção dessas colonialidades? A cidade, em suas profundas contradições, parece existir como entidade na qual a temporalidade está em constante embate: de um lado, há a preservação da memória e a relação com seu passado; de outro, estão as urgências da modernização e do "progresso" que a impele para o futuro. Com suas emergências irrompendo no presente, a cidade parece não só conter o tempo, mas dilatá-lo, encurtá-lo ou congelá-lo. Tal luta, travada entre as direções temporais, abarca grande dimensão das discussões sobre urbanismo: afinal, as cidades são documentos do passado, espaços da experiência corpórea e social do agora ou projetos para um futuro - que encerra sempre uma incógnita e uma esperança - melhor?

Poderíamos separar aqui duas abordagens da história urbana ocidental: uma que lida com a cidade como continente de seus diversos objetos arquitetônicos e paisagísticos, numa postura que poderíamos denominar positivista, e outra que percebe a cidade como o objeto em si: como local das experiências da vida ou como experiência da vida ela mesma; como arena de luta ou como nosso próprio monstro civilizatório, como na tradição da Escola dos Annales ou dos autores marxistas. Porém essa dualidade constitui a contradição fundamental do território da cidade: sua existência como continente da experiência urbana, bem como sua própria conformação, continuamente produzindo uma à outra. A Academia divide a História da Cidade, o Planejamento Urbano e a Teoria urbanística numa forma analítica de organizar essa contradição fundamental, no entanto, essa prática parece ter como consequência, no pensamento tanto da história quanto do projeto, uma noção de que o território somente reflete a experiência humana do passado e promoverá a experiência humana do futuro, ficando o presente situado em um nó górdio no qual as irrupções das emergências se apresentam como eventos apartados do discurso urbano. Porém o presente, como nos lembra Walter Benjamin, é monumento da cultura de um povo, e "nunca houve um monumento da cultura que não fosse também um monumento da barbárie" (Benjamin, 1987, tese 7).

Talvez um caminho possível para decolonizar a escrita sobre a cidade latino-americana passe, justamente, pela intersecção dos fatos da história de nossa urbanização com a espacialização das estruturas de 


\section{SÃOPAULO15 17 LISBOA $25 \sim 26$ JUN 2020}

dominação colonial conformadoras de nossa experiência territorial; ou seja, na incorporação do movimento dialético em sua própria escrita historiográfica. Uma pesquisa da história da cidade que não só aponte essa contradição, mas apreenda, em seu próprio método histórico, as formas como o projeto, o discurso sobre o projeto e a experiência do projeto urbano se interrelacionam com as estruturas da colonialidade do Ser, do Poder e do Saber. Uma pesquisa capaz de pensar, dialeticamente, como compreendemos o território, como falamos do território e como planejamos o território reproduzindo essas estruturas históricas de dominação. Como postula Antonio Carlos Robert Moraes: "A determinação colonial se inscreve nos padrões de organização do espaço, na conformação da estrutura territorial, nos modos de apropriação da natureza e de usos dos recursos naturais, na fixação de valor ao solo e nas formas de relacionamento entre os lugares" (1999, p. 43).

Moraes chama de "determinação colonial" uma forma de organização que se impõe à colônia e nela toma contornos fixos. Essa cosmogonia do ser-colônia (devir colonial?) é determinante para a sua organização, e, portanto, para a produção do seu espaço. É dentro dessa dialética que se insere o problema aqui exposto. Os processos de independência e criação das repúblicas latino-americanas, bem como a formação dos Estados e a criação de identidades nacionais, surgem dentro dessa lógica da ausência de ruptura com o passado colonial. E, no que tange à organização espacial, promovemos, sim, colônias independentes, cujas metrópoles são fundadas internamente, mas os processos de exploração dão-se tanto no sistema global quanto nas relações internas. Dialeticamente, portanto, o espaço urbano da América Latina nos conta a história da colonização bem como a produz.

\section{Raça como fator constitutivo da produção do espaço urbano nas Américas}

Edmundo O'Gorman (2012), em "La Invención de America”, afirma que não se pode imaginar o surgimento da América como um mero aparecimento físico de um vasto pedaço de terra, mas como a própria invenção do Ocidente: a inauguração de um novo sistema mundial que envolverá uma nova forma de se lidar com a produção econômica, com o território e com o Outro. Invenção essa que será fundamental, como aponta Aníbal Quijano (2000), ao tratar do significado de colonialidade, tanto para o surgimento da própria modernidade europeia, por meio do desenvolvimento propiciado pelo grande afluxo de capital gerado pela colonização, quanto para a fundamentação da noção de um Outro "inferior", passível de ser apagado e escravizado, Outro esse que será representado pelos povos indígenas e africanos. O ser latino-americano, portanto, funda-se sobre essa dupla operação: a de ser signo do desenvolvimento e signo da violência, tanto a física, quanto a do sistemático silenciamento de saberes e culturas que não se inserem no sistema moderno.

Tal movimento de modernização e violência se torna uma constante no processo histórico das Américas ao longo dos quinhentos anos que se seguem à chegada de Colombo; ainda que perpassem diversos ciclos que possuem especificidades socioeconômicas relativas tanto aos desenvolvimentos internos das Américas, quanto às mudanças em escala global. Nesse processo de invenção imagética e mitológica, de proporção tão imensa, surge, inclusive, a ideia de Thomas Morus para criar a palavra utopia, em 1516, a partir do prefixo grego de negação justaposto à palavra lugar: o não-lugar. ${ }^{1} \mathrm{E}$ o lugar inexistente é uma cidade ideal, a Cidade do Sol, no "Novo Mundo" - cidade na qual se escapa dos defeitos que Morus percebe em seu próprio país, a Inglaterra. A construção da cidade latina poderia ser mitificada como a cidade ideal, a cidade perdida, o

\footnotetext{
${ }^{1}$ Thomas Morus na grafia latina, ou Thomas More, na grafia inglesa, foi chanceler de Henrique VIII e escreve Utopia (1516), sua concepção de sociedade ideal, a partir do seu amplo conhecimento do funcionamento do Estado.
} 


\section{SÃO PAULO15 17 LISBOA 25 26 JUN 2020}

Eldorado. Materialmente, porém, o processo que se dá é exatamente o oposto: um processo que se estrutura a partir da ruptura, como coloca o antropólogo chileno Alejandro Haber:

La violencia nos constituye, constituye al mundo. ¿Pero de qué maneras? Seccionando las relaciones constitutivas del mundo, separando las partes seccionadas, y ensamblándolas de acuerdo a las reglas del colonizador. Codificando estas reglas en conocimiento hegemónico (religión, ciencia, leyes, etc.). El carácter hegemónico de ese conocimiento nos hace partícipes de la violencia, que nos constituye inmanentemente. Las cisuras operadas en el mundo se vuelven inmanentes a la subjetividad mediante las tecnologías pedagógicas del Estado (catecismo, escolaridad, institucionalización). Pero también se desplazan como ruptura al mundo objetivo, mediante la operación disciplinaria que en sus marcos epistemológicos - no tan solo en sus contenidos teóricos - consagra e inocula la episteme occidental. (2011, p. 29-30)

Haber explicita algumas das formas sobre como o conhecimento hegemônico se torna imanente à constituição do sujeito, sendo o sujeito colonizado, portanto, impregnado da violência que disciplina corpos e espíritos em prol da visão epistemológica dominante. A América surge a partir de ato de violência, e essa violência se mantém a partir da subalternização do Outro, por sua vez criado como a contraparte de um serente-universal: o homem branco. Assim, todo sujeito não-branco se torna, a partir do processo colonial, um outro não-humano, subalterno, inferior, sub desenvolvido, cujo conhecimento não tem valor, os hábitos são selvagens, a aparência é indesejável e o corpo é subjugado com a única finalidade de servir ao "branco". A seguinte passagem de Lewis R. Gordon, no prefácio a "Peles negras, máscaras brancas", explica bem essa questão:

$\mathrm{Na}$ maioria das discussões sobre racismo e colonialismo, há uma crítica da alteridade, da possibilidade de tornar-se o Outro. Fanon, entretanto, argumenta que o racismo força um grupo de pessoas a sair da relação dialética entre o Eu e o Outro, uma relação que é a base da vida ética. A consequência é que quase tudo é permitido contra tais pessoas, e, como a violenta história do racismo e da escravidão revela, tal licença é frequentemente aceita com um zelo sádico. A luta contra o racismo anti-negro não é, portanto, contra ser o Outro. É uma luta para entrar na dialética do Eu e do Outro. (2008, p. 16)

Já Walter Mingolo (2007) denomina justamente o projeto colonialista como o lado sombrio da modernidade, ou seja, a própria chegada dos europeus às Américas cria a condição material para o desenvolvimento do que chamamos de modernidade: o desenvolvimento a partir do paradigma da racionalidade ou o acirramento da ideia da detenção de racionalidade ocidental. Esse projeto cria a ciência moderna (a revolução científica), o iluminismo e o positivismo. Porém sua gestão se fundamenta na ideia de que o ser humano precisa ser racional como forma de sair de seu estado selvagem, ou do estado primitivo no qual ocorrem guerras e misticismos; e, como consequência disso, existe a separação entre quem são os civilizados, ou seja, quem chegou a esse estado, e quem não.

Essa divisão promove a ideia de que povos "selvagens" devem, para se civilizar, abandonar seus saberes tradicionais e se adaptar à forma de pensamento moderna. Essa é a lógica que promove a desumanização dos povos considerados inferiores, tornando-os passíveis, portanto, de serem escravizados ou mortos, já que 


\section{SÃO PAULO15 17 LISBOA 25 26 JUN 2020}

não são humanos. Sua única redenção seria alcançada graças à "civilização", porém trata-se rapidamente de concluir, cientificamente, que isso é impossível, pois esses povos não possuem as condições biológicas para tal tento. O racismo, portanto, é parte intrínseca do projeto moderno. Com ele temos duas frentes: a eliminação das epistemologias produzidas pelo "Outro" e a subalternização de seus indivíduos ao pensamento europeu.

\section{As contradições na produção do espaço: território como epistemologia}

A lógica da modernidade europeia, das luzes, é a de um homem universal racional. Como vimos, o universal aqui é o homem branco, e a racionalidade é restrita à produzida a partir dos padrões determinados pela Europa. Assim sendo, tudo produzido fora desse padrão está fora da lógica do moderno de forma que, finalmente, chegamos ao cerne da nossa questão: como isso se expressa na produção do espaço urbano latino-americano?

Primeiramente, na impossibilidade, como diria Gaytri Spivak (2014), do subalterno falar, ou seja, as formas de sociabilidade e os modos de vida das populações subalternizadas são desconsiderados no planejamento das cidades. Em segundo lugar, evidencia-se na noção de que o planejamento urbano é um ato técnico, portanto neutro, que responde a um ideal universalizável, de forma que as soluções urbanísticas desconsideram suas necessidades em micro escala, levando em conta somente a escala geral dos planos urbanos. E, por último, aparece na cisão completa a que nos referimos no início do texto: a cidade das populações subalternizadas não é considerada a cidade legal, ou seja, a cidade na qual a lei incide, sendo, portanto, um território selvagem, intocado pelas benesses da infraestrutura estatal. Sendo assim, em seus aspectos materiais, quais são as contradições, a partir das formas de produção desse espaço, que podem lançar luz sobre os diversos aspectos de nossa relação com nossos territórios?

Levando em conta a noção de que o espaço opera não somente como o reflexo das condições econômicas e sociais, mas ele próprio se cria nessa lógica que, por sua vez, atua nas formas de apropriação desse espaço, deparamo-nos, aqui, com duas questões centrais. Primeira, a produção desse espaço na periferia do sistema capitalista. Em uma posição de subalternidade, quais as consequências da relação com o capital industrial, a periferia operaria numa lógica como espaço das classes oprimidas? Para a segunda questão, no cenário da América Latina, temos o fator, como dissemos acima, da subalternização a partir do viés da raça. O que se torna bastante claro é que a reprodução da luta de classes dentro do espaço, ou seja, a exploração da produção de valor no território da cidade contemporânea latino-americana, reproduz internamente o sistema colonial: se na Europa o capital modela a cidade tirando o direito dos trabalhadores à própria, para usarmos o vocabulário lefebvriano (2008), na periferia essa lógica se sobrepõe à retirada dos povos subalternizados, ou seja, indígenas e povos da diáspora.

Temos aqui a proposta para a interseção metodológica entre uma dialética espacial e uma decolonização da história dos nossos territórios: para tanto é preciso a compreensão das contradições internas ao capitalismo periférico que sobrepõe classe e raça em sua lógica produtiva. 


\section{SÃO PAULO15 17 LISBOA $25 \sim 26$ JUN 2020

\section{Referências bibliográficas}

\subsubsection{Obra completa}

BENJAMIN, W. (1987) Teses sobre a história. In W. BENJAMIN Obras escolhidas. Magia e técnica, arte e política. Ensaios sobre literatura e história da cultura (3 ed., vol. 1, pp. 222-232). São Paulo: Brasiliense.

FANON, F. (1968). Sociología de una revolución. Ciudad de México: Era.

-. (1979). Os condenados da terra. Rio de Janeiro: Civilização Brasileira.

—. (1980). Em defesa da revolução africana. Lisboa: Livraria Sá da Costa.

- (2002). Le Damné de La Terre. Paris: La Découverte \& Syros.

-. (2008). Pele negra, máscaras brancas. Salvador: EDUFBA.

GORDON, L. R. (2008). Prefácio. In FANON, F. Pele negra, máscaras brancas (11-24). Salvador: EDUFBA.

LAFEBVRE, H. (2008). Espaço e Política. Belo Horizonte: Editora UFMG

MIGNOLO, W. D. (2007). La idea de América Latina. La herida colonial y la opción decolonial. Barcelona: Gedisa.

O'GORMAN, E. (2012). La invención de América. Investigación acerca de la estructura histórica del nuevo mundo y del sentido de su devenir. México: Fondo de Cultura Económica.

QUIJANO, A. (2000). Colonialidad del poder, eurocentrismo y América Latina. In E. LANDER (Ed.), La colonialidad del saber: eurocentrismo y ciencias sociales. Perspectivas latinoamericanas (201-246). Buenos Aires: Clacso.

SOJA, E. W. (1996). Thisdspace. Jorneys to Los Angeles and Other Real-and-Imagined Places. Oxford: Blackwell.

SPIVAK, G. (2014). Pode o subalterno falar? Belo Horizonte: Editora UFMG.

\subsubsection{Revistas}

https://www.tucavieira.com.br/paraisopolis (Acessado 24/07/2020).

BALLESTRIN, L. (2013). América Latina e o giro decolonial. Revista Brasileira de Ciências Políticas, (Brasília), 11, 89-117. https://doi.org/10.1590/S0103-33522013000200004

HABER, A. (2011). Nometodología Payanesa. Notas de metodología indisciplinada (con comentarios de Henry Tantalean, Francisco Gil García y Dante Angelo). Revista Chilena de Antropología (Santiago de Chile), 23, 9-43. https://doi.org/10.5354/0719-1472.2011.15564

MIGNOLO, W. D. (2008). Desobediência epistêmica. A opção descolonial e o significado de identidade em política. Cadernos de Letras da UFF. Dossiê: Literatura, língua e identidade (Rio de Janeiro), 7(34), 287-324.

—. (2017). Desafios decoloniais hoje. Epistemologias do Sul (Foz do Iguaçu), 1(1), 12-32. 


\section{SÃO PAULO15 17 LISBOA 25 26 JUN 2020}

Seminário Internacional de

Seminario Internacional de Investigação em Urbanismo Investigación en Urbanismo

MORAES, A. C. R. (1999). Notas sobre formação territorial e políticas ambientais no Brasil. Revista Território, (São Paulo), 7(4), 43-50.

\subsubsection{Fontes eletrônicas}

https://www.tucavieira.com.br/paraisopolis (Acessado 24/07/2020). 